\title{
WebGIS design and development of water quality test of rural domestic
}

\section{sewage Dianchi Lake Basin}

\author{
Pengju Quan ${ }^{1}$, Hong Liang ${ }^{1, a}$, Xuehui Lu ${ }^{1}$ and Ruitao Cui ${ }^{2}$ \\ ${ }^{1}$ School of information Science and Engineering, Yunnan University, China \\ ${ }^{2}$ Dianchi Lake Water Treatment Company Limited in Kunming, China \\ aynliangh@126.com
}

\begin{abstract}
Keywords:Dianchi Lake Basin, Rural domestic sewage, Water quality test, WebGIS
\end{abstract}
Abstract. Rural domestic sewage is an important cause of water pollution in Dianchi. Accurately grasping the spatial distribution of sewage is the basic condition for harnessing Dianchi's water pollution. By collecting water samples from various parts of the Dianchi River Basin and conducting laboratory tests, the spatial distribution of Dianchi sewage is determined. This paper mainly introduces the development and design of WebGIS platform for the analysis of rural living pollution in Dianchi River Basin. The structure, design and function of the platform are introduced in detail. Finally, the results are displayed directly through the thermal diagram.

\section{Introduction}

Since ancient times, human civilization has been accompanied by water. Dianchi is the largest lake in the Yunnan Guizhou Plateau. It is an important natural condition for Kunming to survive and develop. The Dianchi river basin is one of the most highly populated areas in Yunnan, the highest degree of industrialization and urbanization, the most developed economy, the growth of investment and the most dynamic social development. The Dianchi river basin is a region with good natural and social and economic conditions in Kunming. Population and industrial agglomeration play an important role in the regional social and economic structure. Since the reform and opening up, grain production has been developing steadily, and flower, vegetable cultivation, flue cured tobacco production, animal husbandry and other industries have developed rapidly. It has formed an industrial system mainly based on resource utilization, agricultural planting, mineral exploitation and processing. The development of agricultural industrialization, especially vegetable and flower production, has reached a certain level. In 2000, the population of the river basin was 2 million 200 thousand, accounting for $6.5 \%$ of the population of Yunnan province. The Dianchi River Basin accounted for $0.7 \%$ of the land area in Yunnan Province, but it created 24\% GDP of the province. It was the most dynamic area in Yunnan province.

In recent decades, with the rapid growth of industrialization and urbanization, the rapid growth of population has brought great pressure to the water environment of the Dianchi River Basin. The contradiction between supply and demand of water resources is becoming more and more prominent, the pollution load of water body is gradually aggravated, the ecosystem has been damaged day by day, and the service power of the ecosystem can degenerate day by day. Dianchi is listed as one of the three major lakes in China. The situation of water pollution in Dianchi is still very serious

With the rapid development of the rural economy, the increasing population and the change of life style, the emission of rural living pollutants has increased rapidly. The rural domestic sewage 
has become an important pollution source of pollution in Dianchi. Because of the randomness of the production and discharge of rural domestic sewage, it is difficult to study the rural domestic sewage.

The rural sewage treatment facilities in the Dianchi River Basin are mainly divided into municipal sewage treatment stations, integration, three pools / ecological ponds according to different processing technologies. The data source of this collection is from the town sewage treatment station. The town sewage treatment station is a large sewage treatment facility built on the ground. It covers a large area and has a large population of service. Its construction includes CASS reaction pool, intermediate pool, sedimentation tank, CASS and advanced treatment of sewage treatment technology. By testing and testing the water quality of the outlet and the influent of the town, the proportion of the corresponding components is obtained. Sample collection and monitoring are carried out in accordance with relevant national standards, regulations, monitoring technical specifications and relevant quality control manuals. In the process of sample collection and inspection, the examination and verification are carried out many times, and a number of samples are selected for laboratory comparison to ensure the accuracy and reliability of the testing work.

In this study, 176 rural domestic sewage points were monitored for 5 months, and the indicators of rural domestic sewage in the Dianchi basin were obtained, which not only provided reference for further research on rural domestic sewage in Dianchi basin, but also provided basic data and data for the further treatment of rural living pollution in the Dianchi Basin for a period of time. Support. The main content is to monitor the CODcr, T-N, T-P, NH3-N, pH, Suspended solid, Biochemical Oxygen Demand in the rural domestic sewage of different economic income levels, different seasons and different ways of living in the Dianchi River Basin, and collect 747 samples. The data of 5229 samples is represented by the large sample number. The principles of good sex and high reliability are finally displayed through the WebGIS platform.

\section{Design and implementation of spatial database}

Designing and implementing the database of the system is the foundation of the whole system implementation. The design of spatial database not only needs to follow the general criteria set up in the database completely, accurately reflect the connection between the data, but also reduce the data redundancy and data duplication as much as possible so that the spatial database has good performance, and the village and town sewage treatment facilities in the Dianchi basin of Kunming should be fully considered. The operation status and the application requirements of the relevant management business of the sewage treatment and management department.

The database of WebGIS system in the village and town sewage treatment facilities in the Dianchi River Basin combines the geographical elements, object classes and data sets according to a certain model and standard. It is built in the Geodatabase database, and the creation process of the spatial database and the management process of the spatial data are implemented in ArcCatalog.

In order to make the design, development, maintenance and management of the system more convenient, we need to build a clearer database. The WebGIS system database of the rural domestic sewage water quality analysis of the Dianchi basin is stored according to the hierarchical data objects, and the data in the whole geographic database are classified and stored: the basic data and the professional data. Among them, the basic data layer is Kunming satellite remote sensing base map, and professional data refer to the composition of rural sewage. 


\section{Platform Design}

Architecture Design. The water quality test of rural domestic sewage platform that adopts the B/S structure, as shown in Fig.1 :

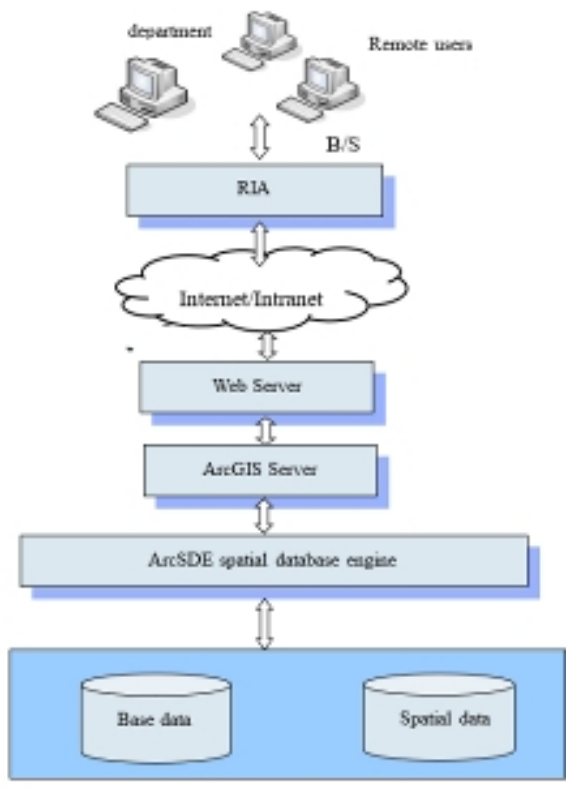

Fig.1 Network Structure Diagram

The $\mathrm{B} / \mathrm{S}$ part is water quality test of rural domestic sewage platform and network management platform, which achieves rural domestic sewage treatment, remote data entry and reporting, generating report, analysis data, and with which remote users can visually browse, query and analyze spatial information through Web browser based on Internet.

Function Design.In this paper, GIS, GPS, WebGIS and spatial database technology are used to design and develop the village and town sewage treatment facility WebGIS platform in Dianchi basin, and realize the information and visualization management. The main functions are as follows:

(1) Login interface. Through this interface, fill in the account number and password to enter the system.

(2) Main interface and basic operation tools. Enlarge: click plus to enlarge. Reduction: click reduction to reduce; location: click location, locate to the user's current position and magnify; default range: restore to the default range interface; Hawk Eye: quick view of the map.

(3) Attribute query. Click the property query icon and the attribute information of its query result will appear next to it. as shown in Fig.2:

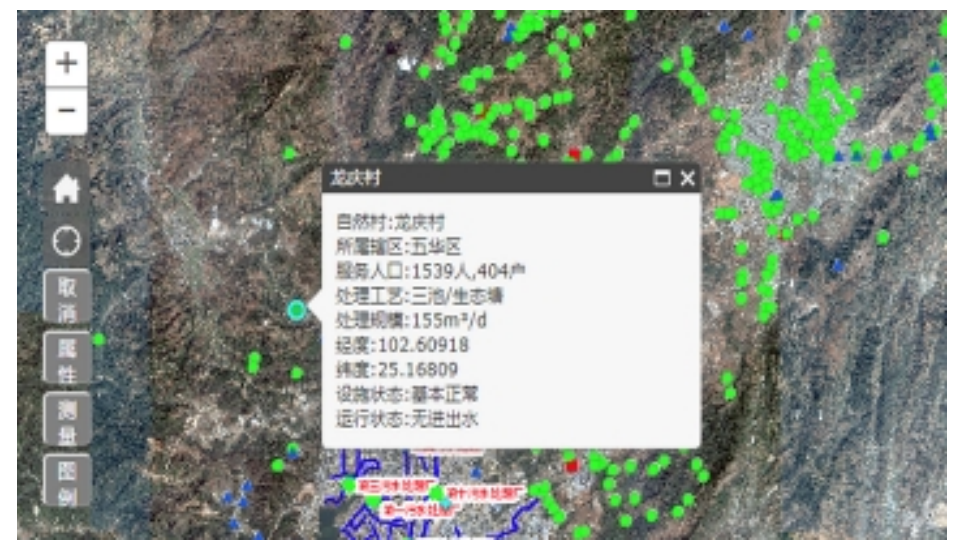

Fig.2Atrribute Query 
(4)Screening query. Some of them are inquired through their respective jurisdictions and processing technology. The other part is spatial information query. Click the rectangle box to draw the region of interest on the map. The selected information is exported to Excel table, which is convenient for users. as shown in Fig.3:

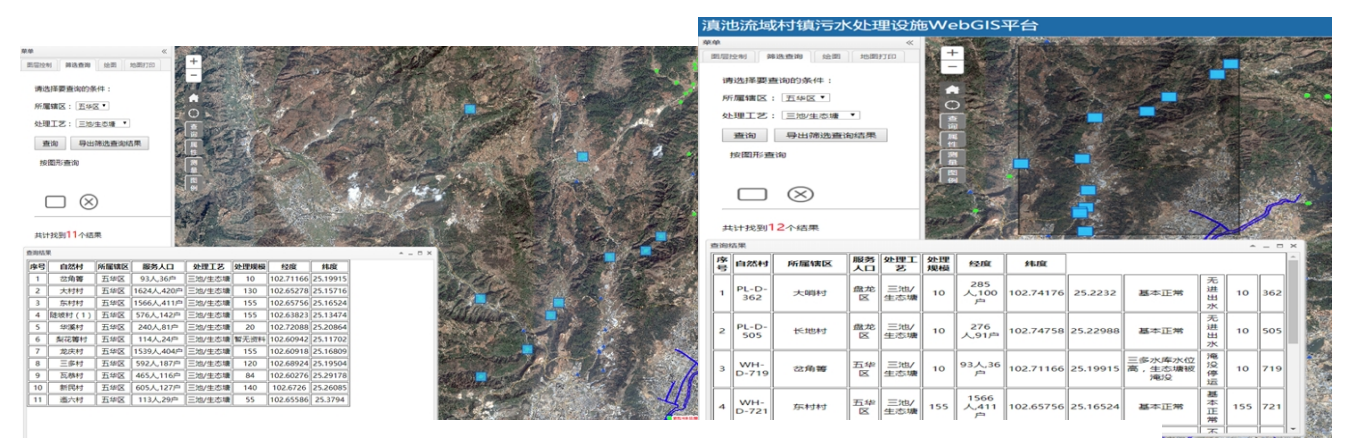

Fig.3 Network Structure Diagram

(5) Fuzzy query. Users can query through the first or two fields of village name, jurisdiction and number. as shown in Fig.4:
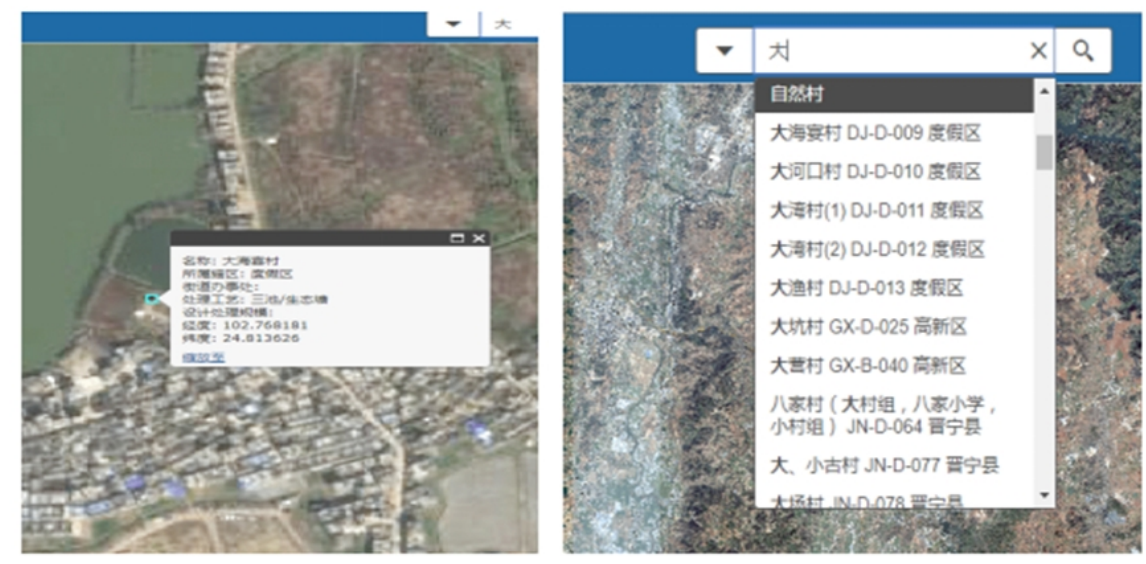

Fig.4 Fuzzy Query

(6) Map printing function. Custom print range and print content, output map

(7) Measuring function.measuring the length and area of any place on the map, and also selecting the unit of measurement.

(8) Layer control. which can selectively display the required layer.

\section{Conclusions}

Through the analysis of the WebGIS platform of the water quality test of the rural domestic sewage in the Dianchi basin, the spatial distribution of the domestic sewage in Dianchi can be quickly determined and the data before and after the treatment are displayed through the comparison of the platform. The platform can provide reference for further research on rural domestic sewage in Dianchi basin, and provide basic data and data support for further management of rural living pollution in Dianchi basin for a period of time.

\section{Acknowledgements}

First of all, I would like to extend my sincere gratitude to my supervisor, Hong Liang, for her instructive advice and useful suggestions on my thesis. I am deeply grateful of her help in the completion of this thesis. 
I am also deeply indebted to all the other tutors and teachers in Translation Studies for their direct and indirect help to me.

Special thanks should go to my friends who have put considerable time and effort into their comments on the draft.

Finally, I am indebted to my parents for their continuous support and encouragement.

\section{References}

[1] Shenya Liu.Design and Development of Wastewater Treatment WebGIS Platform in villages and towns of Dianchi Lake Basin[D],2018, Yunan University.

[2] Xinyu Wang,Feng Zhou,Xuan Yi,Huaicheng Guo.Study on the Stages of Major Sediments in Dianchi Lake[J].Environment Science,2014

[3] Shimin Zhao,Daowei Wang,Xianming Li,Shigang Li.Assessment on heavy metals pollution in surface sediments of Dianchi Lake and its estuaries[J]Environment Chemistry,2014

[4] Zhongjie Li,Yixin zhen,DaWei Zhang,Jinbi Ni.Impacts of 20-year socio-economic development on aquatic environment of Lake Dianchi Basin[J]Lake Science,2012, 24( 6) : $875-882$

[5] Pixiang Wang,Landi He,GuoQiang Zhi,Yuhua Yang.Investigation on treatment of scattered sewage in rural areas of Dianchi River Basin[J]Environmental Science Survey,2012, 31 ( 5)

[6] Tingting Yan,Honghua Wang,Zhixu Sun,DexiWu,Xuming Ning.Sewage discharge coefficient of rural domestic sewage in Dianchi Basin[J]Environmental Science Survey,2010, 29 (4):46 $-48$

[7] Jia He,Xiaomei Xu,Yan Yang.Effects and problems of water environment comprehensive treatment in Dianchi [J]Lake Science,2015, 27( 2) : 195-199

[8] Jun Liu, Jianjun Tan, Changgao Shao. The WebGIS Framework Design and Implementation based on Flex [A]. Computer Engineering, 2010. 